\title{
Sildenafil citrate for the management of asymmetrical intrauterine growth restriction and its effect on umbilical artery Doppler
}

\author{
Laila E. Abd El Fatah"*, Diaa A. Elnashar ${ }^{2}$, Zeinab M. Abo Elabass ${ }^{3}$, Abdou S. Ait-Allah ${ }^{4}$
}

\begin{abstract}
${ }^{1}$ Obstetrics and Gynecology Department, Faculty of Medicine, Fayoum University, Fayoum, Egypt
${ }^{2}$ Obstetrics and Gynecology Department, Faculty of Medicine, Assuit University, Assuit, Egypt

${ }^{3}$ Obstetrics and Gynecology Department, Faculty of Medicine, Aswan University, Aswan, Egypt

${ }^{4}$ Obstetrics and Gynecology Department, Faculty of Medicine, Sohag University, Sohag, Egypt
\end{abstract}

Received: 26 December 2021

Revised: 28 January 2022

Accepted: 29 January 2022

\author{
*Correspondence: \\ Dr. Laila E. Abd El Fatah, \\ E-mail: lailaezzat972000@gmail.com
}

Copyright: (C) the author(s), publisher and licensee Medip Academy. This is an open-access article distributed under the terms of the Creative Commons Attribution Non-Commercial License, which permits unrestricted non-commercial use, distribution, and reproduction in any medium, provided the original work is properly cited.

\section{ABSTRACT}

Background: Asymmetrical intrauterine growth restriction IUGR occurs when there is uteroplacental insufficiency. Sildenafil citrate phosphodiasterase- 5 inhibito is a potent vasodilator, which selectively inhibits phosphodiesterase-5 and, as a consequence, enhances the action of cyclic guanosine monophosphate which is the second messenger of NO. Hence, the trial was used for improving uteroplacental perfusion through enhancing vasodilatation of myometrial small arteries boosting flow within uteroplacental bed. The aim was to evaluate the efficacy of adding sildenafil citrate to low dose aspirin in treatment of asymmetrical IUGR through its effect on uteroplacental blood flow guided by Doppler ultrasound.

Methods: Our study was a prospective double-blinded, randomized, controlled trial. Recruitment of participating women was from the obstetric outpatient clinic of Aswan university hospital. 100 patients included in the study and randomized in two groups. The first group was 50 patients assigned sildenafil with low dose aspirin and the second group was 50 patients assigned placebo with low dose aspirin.

Results: As regard the outcomes, the study demonstrated that using of SC and LDA were effective in increasing estimated fetal weight and in improvement of umbilical artery umbilical artery Doppler (UAD) indices RI and PI for pregnancy complicated with IUGR compared with the control group.

Conclusions: Sildenafil citrate is a promising treatment for IUGR fetuses with prolongation of pregnancy and improvement of fetal birth weight, umblical Doppler indices UDI, decreases days needed in PCU.

Keywords: Fetal growth restriction, Small for gestational age, Umbilical artery Doppler, Sildenafil citrate management

\section{INTRODUCTION}

IUGR is defined as a fetus who is at or below the 10th percentile in weight for its gestational age as adopted by the ACOG (American college of obstetricians and gynecologists). ${ }^{1}$ One of the main pathophysiology of asymmetrical IUGR is defective uteroplacental flow either unexplained or secondary to maternal conditions like preeclampsia. $^{2}$

Studies have demonstrated that sildenafil citrate significantly enhances vasodilation of myometrial small arteries and is also associated with fetal weight gain which offers a potential therapeutic possibility for IUGR. ${ }^{3} \mathrm{We}$ 
used sildenafil in purpose to improve blood flow in placental bed and improve fetal growth.

\section{Aim}

The aim was to evaluate the efficacy of adding sildenafil citrate to low dose aspirin in treatment of asymmetrical IUGR through its effect on uteroplacental blood flow guided by Doppler ultrasound.

\section{METHODS}

Eligible women who gave their informed consent were randomized to two groups. Group A: received sildenafil citrate $20 \mathrm{mg}$ orally/8 hours and low dose acetyl salicylic acid $150 \mathrm{mg} /$ day; group B: received low dose acetyl salicylic acid $150 \mathrm{mg} /$ day and placebo. All participents underwent complete history, clinical examination of the women by measuring BP LL oedma fundal level and symphysial fundal height ultrasonography: in every visit, we measured estimated fetal weight, biparietal diameter, head circumference, abdominal circumference and amniotic fluid index and any changes before and after administration of sildenafil or placebo was noted down. Non stress test was an appropriate surveillance method had been shown to correlate with fetal well-being. Doppler flow of the umblical artery, middle cerebral artery and uterine artery every 2 weeks and any changes before and after administration of sildenafil was noted down. CBC was done to exclude anemia.

\section{Technique of Doppler}

Pulsed wave Doppler ultrasound studies of the fetal circulation were performed with a colour Doppler system VolusonS8 with a 3.5 or $5-\mathrm{MHz}$ curved array transducer with spatial peak temporal average intensities below 100 $\mathrm{mW} / \mathrm{cm}^{2}$. The high-pass filter was set at $125 \mathrm{~Hz}$. The size of the sample was adapted to the vessel diameter to cover it entirely. All recordings used for measurements were obtained in the absence of fetal breathing movements and when the fetal heart rate was between 120 and $160 \mathrm{bpm}$. The angle between the ultrasound beam and the direction of blood flow as low as possible to be less than $50^{\circ}$. Umbilical artery Doppler studies were performed in the same sitting from a free floating portion of the cord during fetal quiescence and apnea.

\section{Measurements}

Umbilical artery Doppler studies were performed from a free floating portion of the cord during fetal quiescence and apnea. Measuring peak systolic velocity $\mathrm{S}$, end diastolic velocity $\mathrm{D}$.

Three indices were calculated for knowing vascular resistance.

$\mathrm{SD}$ ratio $=\frac{\text { systolic }}{\text { diastolic }}$
Resistance index $(\mathrm{RI})=\frac{\text { systolic velocity-diastolic velovity }}{\text { systolic velocity }}$

Pulsatility index $(\mathrm{PI})=\frac{\text { systolic }- \text { diastolic }}{\text { a temporal average frequency over } 1 \text { cardiac cycle }}$.

These indices were all based on the maximum Doppler shift waveform PI gave a broader range of values where there was no end-diastolic flow.

\section{Outcomes}

The primary outcome was the Doppler changes in umbilical artery and resultant effect on the fetal growth. The secondary outcome was number of babies admitted to NICU.

\section{Statistical analysis}

Patients data was recorded in spread sheet Microsoft office excel 2010. The statistical tests were performed using SPSS Inc., Chicago, Version16. We used the one way Anova test to analyze continuous variables. The Chi square $\mathrm{x}^{2}$ test was used to analyse categorical variables. $\mathrm{P}<0.05$ was considered statistically significant. Quantitative data were described using mean and standard deviation for normally distributed data while abnormally distributed data was expressed using median, minimum and maximum. For normally distributed data, comparison between two independent population were done using independent $t$ test.

For abnormally distributed data, correlations between two quantitative variables were assessed using Spearman coefficient. Multivariate logistic regression was used. Significance test results were quoted as two-tailed probabilities. Significance of the obtained results was judged at the $5 \%$ level.

\section{RESULTS}

Table 1 shows the baseline characteristics of the study participants and demonstrated that both study groups were homogenous at the time of recruitments as indicated by having no statistically significant differences between the two groups age, residence, occupation, parity and level of education.

Table 2 shows that clinical and ultrasonic data of both study groups at time of recruitment did not have statistically significant difference between the two groups as blood pressure, BMI, symphyseal fundal height and gestational age by last menstrual period and ultrasound.

As shown in Table 3 there was significant difference in EFW after inclusion. EFW was higher in group A compared to the group B after recruitment. 
Table 1: Personal data of the studied groups.

\begin{tabular}{|c|c|c|c|}
\hline Parameters & $\begin{array}{l}\text { Group A }(\mathrm{n}=50) \\
\mathrm{N}(\%)\end{array}$ & $\begin{array}{l}\text { Group B }(\mathbf{n}=50) \\
\mathrm{N}(\%)\end{array}$ & $P$ value \\
\hline \multicolumn{3}{|l|}{ Age (years) } & \multirow{3}{*}{0.622} \\
\hline Mean \pm SD & $27.34 \pm 5.81$ & $27.92 \pm 5.92$ & \\
\hline Range & $18.0-38.0$ & $18.0-38.0$ & \\
\hline \multicolumn{3}{|l|}{ Residence } & \multirow{3}{*}{0.410} \\
\hline Rural & $29(58.0)$ & $33(66.0)$ & \\
\hline Urban & $21(42.0)$ & $17(34.0)$ & \\
\hline \multicolumn{3}{|l|}{ Occupation } & \multirow{3}{*}{0.680} \\
\hline Employer & $20(40.0)$ & $18(36.0)$ & \\
\hline Housewife & $30(60.0)$ & $32(64.0)$ & \\
\hline \multicolumn{3}{|c|}{ Level of education } & \multirow{5}{*}{0.468} \\
\hline Illiterate & $1(2.0)$ & $3(6.0)$ & \\
\hline Primary & $3(6.0)$ & $2(4.0)$ & \\
\hline Secondary & $26(52.0)$ & $20(40.0)$ & \\
\hline High education & $20(40.0)$ & $25(50.0)$ & \\
\hline \multicolumn{3}{|l|}{ Gravidity } & \multirow{3}{*}{0.067} \\
\hline Primigravida & $13(26.0)$ & $23(46.0)$ & \\
\hline Multigravida & $37(74.0)$ & $27(54.0)$ & \\
\hline \multicolumn{3}{|l|}{ Parity } & \multirow{4}{*}{0.158} \\
\hline Primipara & $20(40.0)$ & $27(54.0)$ & \\
\hline Multipara & $29(58.0)$ & $20(40.0)$ & \\
\hline Grand multipara & $1(2.0)$ & $3(6.0)$ & \\
\hline
\end{tabular}

Table 2: Clinical and ultrasonic data of the patients at admission (before treatment).

\begin{tabular}{|c|c|c|c|}
\hline Parameters & Group A $(n=50)$ & Group B $(\mathrm{n}=50)$ & $P$ value \\
\hline Systolic BP & $\begin{array}{l}\text { Mlean } \pm \text { SD } \\
126.50 \pm 11.17\end{array}$ & $\begin{array}{l}\text { Mean } \pm \text { SD } \\
125.60 \pm 11.63\end{array}$ & 0.694 \\
\hline Diastolic BP & $82.60 \pm 6.94$ & $80.80 \pm 7.52$ & 0.216 \\
\hline Weight (kg) & $76.76 \pm 11.43$ & $71.64 \pm 12.59$ & 0.036 \\
\hline BMI $\left(\mathrm{kg} / \mathrm{m}^{2}\right)$ & $29.38 \pm 4.34$ & $28.17 \pm 4.35$ & 0.167 \\
\hline Symphyseal fundal height (cm) & $27.32 \pm 2.77$ & $27.52 \pm 2.49$ & 0.705 \\
\hline Gestational age (LMP) (week) & $33.26 \pm 2.25$ & $33.00 \pm 2.11$ & 0.552 \\
\hline Gestational age (U/S) (week) & $29.70 \pm 1.98$ & $29.44 \pm 1.86$ & 0.501 \\
\hline
\end{tabular}

NB: group A: sildenafil group; group B: control group; BMI: body mass index.

Table 3: Comparison between the estimated fetal weight in study groups.

\begin{tabular}{|llll|}
\hline Estimated fetal weight $(\mathrm{gm})$ & Group A $(\mathbf{n}=\mathbf{5 0})$ & Group B $(\mathbf{n}=\mathbf{5 0})$ & P value \\
\hline At inclusion & Mean \pm SD & Mean \pm SD & \\
\hline 2 weeks after inclusion & $1388.70 \pm 360.72$ & $1303.62 \pm 292.63$ & 0.198 \\
\hline 4 weeks after inclusion & $1578.20 \pm 381.97$ & $1425.76 \pm 299.03$ & 0.029 \\
\hline
\end{tabular}

Table 4: Comparison between the umbilical artery Doppler indices; umbilical artery resistance index, pulsatility index and systolic/diastolic ratio in the two study groups.

\begin{tabular}{|lllll|}
\hline \multirow{2}{*}{ Parameters } & & Group A $(\mathbf{n}=\mathbf{5 0})$ & Group B $(\mathbf{n = 5 0})$ & P value \\
\cline { 3 - 5 } & & Mean \pm SD & Mean \pm SD & 0.347 \\
\hline \multirow{2}{*}{ RI } & At inclusion & $0.73 \pm 0.07$ & $0.71 \pm 0.09$ & 0.347 \\
\cline { 2 - 5 } & 2 weeks after inclusion & $0.71 \pm 0.08$ & $0.76 \pm 0.08$ & 0.036 \\
\cline { 2 - 5 } & 4 weeks after inclusion & $0.63 \pm 0.12$ & $0.81 \pm 0.17$ & 0.000 \\
\hline
\end{tabular}




\begin{tabular}{|lllll|}
\hline \multirow{2}{*}{ Parameters } & & Group A $(\mathbf{n = 5 0})$ & \multicolumn{2}{l|}{ Group B (n=50) } \\
& & Mean \pm SD & Mean \pm SD & Palue \\
& 2 weeks after inclusion & $1.17 \pm 0.25$ & $1.34 \pm 0.35$ & 0.017 \\
\cline { 2 - 6 } & 4 weeks after inclusion & $1.03 \pm 0.19$ & $1.28 \pm 0.26$ & 0.004 \\
\hline \multirow{3}{*}{ S/D ratio } & At inclusion & $3.77 \pm 0.80$ & $3.59 \pm 0.90$ & 0.359 \\
\cline { 2 - 6 } & 2 weeks after inclusion & $3.77 \pm 0.97$ & $3.70 \pm 0.77$ & 0.758 \\
\cline { 2 - 6 } & 4 weeks after inclusion & $3.69 \pm 0.52$ & $3.85 \pm 0.56$ & 0.247 \\
\hline
\end{tabular}

Table 5: Comparison between study groups in birth weight and number of days in NICU.

\begin{tabular}{|c|c|c|c|}
\hline Parameters & Group A $(\mathrm{n}=\mathbf{5 0})$ & Group B $(n=50)$ & P value \\
\hline Birth weight & $1702.00 \pm 367.56$ & $1555.83 \pm 265.25$ & 0.027 \\
\hline \multicolumn{3}{|c|}{ Admission to NICU, N (\%) } & \multirow{3}{*}{0.690} \\
\hline Yes & $39(78.0)$ & $39(81.3)$ & \\
\hline No & $11(22.0)$ & $9(18.8)$ & \\
\hline No. of days in NICU & $3.74 \pm 2.93$ & $6.73 \pm 6.37$ & \multirow{2}{*}{0.035} \\
\hline Median (range) & $3.0(0.0-9.0)$ & $5.0(0.0-21.0)$ & \\
\hline
\end{tabular}

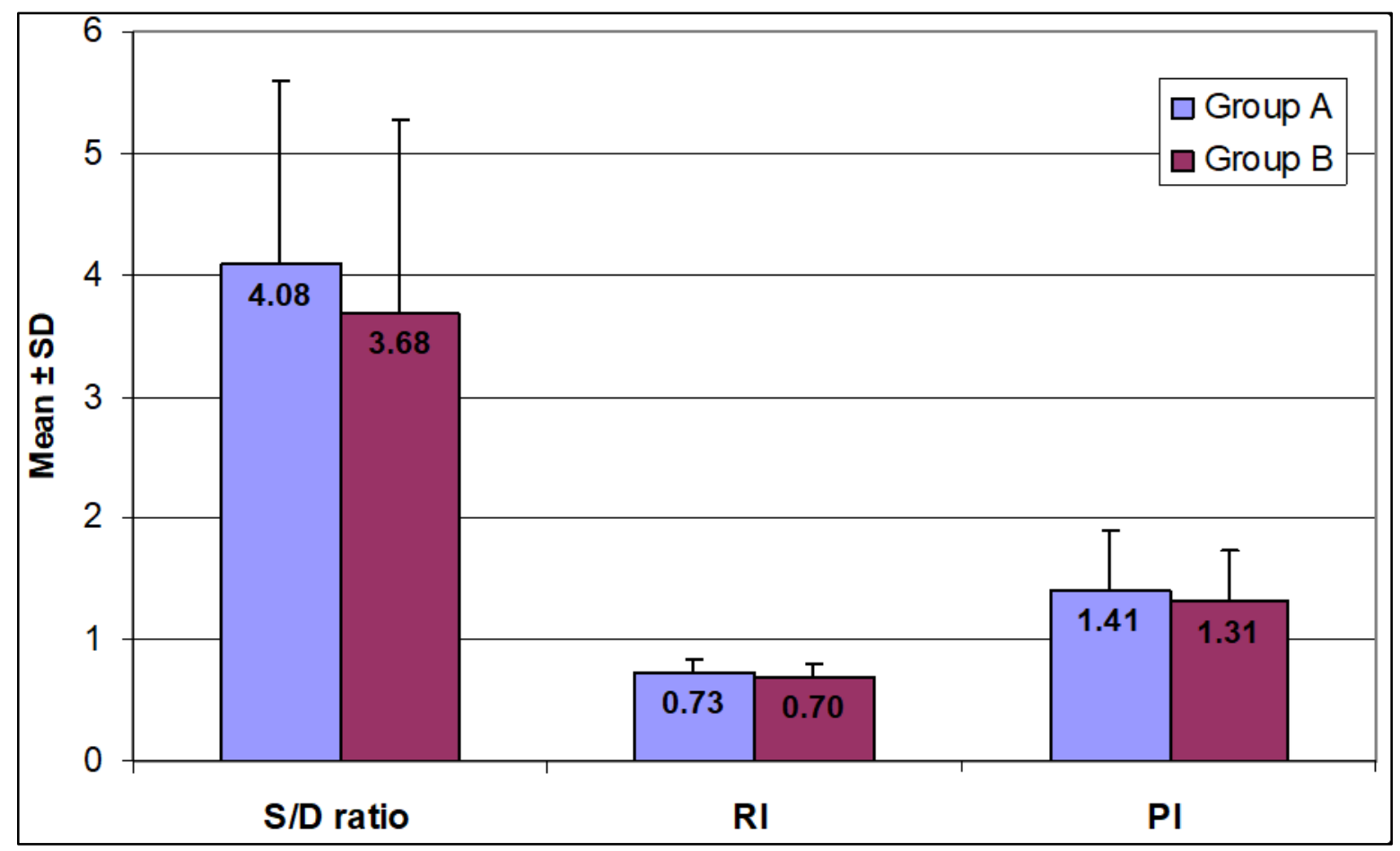

Figure 1: Comparison between the umbilical artery Doppler indices; umbilical artery resistance index, pulsatility index and systolic/diastolic ratio in the two study groups.

Doppler indices of the umblical artery RI and PI summarized in Table four. The umbilical RI and PI both have statistically significant difference between the two study groups. Both indices became significantly lower in group A than in group B after inclusion.

As regard systolic/diastolic ratio of umbilical artery, there was no statistically significant value between the two groups.
As shown in Table five the mean birth weight in group A was significantly higher than in group B at time of delivery $(\mathrm{p}=0.027)$.

The mean number of days of NICU admission was 3.74 in group A compared with 6.73 in group B with p value 0.035 .

The differences between uterine artery doppler indices of group A and B at inclusion. 


\section{DISCUSSION}

IUGR is defined as a fetus who is at or below the 10th percentile in weight for its gestational age as adopted by the ACOG and the RCOG. ${ }^{1,4}$

IUGR represented the second cause of perinatal mortality, after prematurity and it was related to an increased risk of perinatal complication as hypoxemia, low Apgar scores and cord blood acidemia, with possible negative effects for neonatal outcome. . $^{5,6}$

Inspite that there was no definite treatment that proved to improve the pattern of a fetus, modalities tested included maternal nutritional supplemantations, plasma volume expantion, administration of amino acids and medications for the mother such as LDA. ${ }^{8}$

The RCOG recommended the use of LDA in prevention and management of asymmetrical IUGR. ${ }^{7}$ The estimated fetal weight and umbilical artery blood flow increased significantly in LDA group as compared with control group. So, in our study and based on the above recommendation we decided not to deprive our patients from any potentially beneficial treatment and to include LDA in both arms of our study. Sildenafil citrate emerged as a potential candidate for the treatment of IUGR. Also, it had been proposed as a potential therapeutic strategy to maintain placental function. ${ }^{9}$

The present study demonstrated that using of SC and LDA were more effective than using of LDA and placebo in improvement of UAD indices RI and PI. All previous studies agreed on the beneficial effect of SC therapy on Doppler UA blood flow.

Elsayed et al tested the potential for sildenafil to improve UAD indices in study involved 30 asymmetrical IUGR patients, they were 26-32 weeks with singleton spontaneous pregnancy, they agreed with our study and reported significant improvement in Doppler indices in the sildenafil group. ${ }^{10}$ The administration of oral sildenafil 20 mg twice daily for 6 weeks improved Doppler indices in umbilical artery and cerebroplacental ratio.

The present RCT showed that administration of $20 \mathrm{mg} \mathrm{Sc}$ three times daily and LDA for pregnant women with IUGR associated with significant increase in estimated fetal weight compared with the LDA alone.

This finding was in accordance with study by Ferreira et al his study included 19 hospitalized pregnant women who received sildenafil for severe IUGR. ${ }^{11}$ Sildenafil was started at an average of 25 weeks +3 days in dosage of 20 mg orally 3 times/day until delivery. Before sildenafil, estimated average fetal weight was $558 \mathrm{~g}$ and increased to an average of $807 \mathrm{~g}$ at delivery and with an average weight gain of $249 \mathrm{~g}$. However, there was no control arm in his study.
Another study done by Singh et al on effect of sildenafil on IUGR, which showed improvement in fetal weight of $63 \%$ of cases in sildenafil group compared to $20 \%$ of cases in non-treated group. ${ }^{12}$

Dadelszen et al tested the potential for sildenafil to improve fetal growth in an open-label pilot study. ${ }^{13}$ Ten women with pregnancies affected by severe early-onset FGR, where the chance of intact fetal survival was felt to be less than $50 \%$, accepted the option of taking $25 \mathrm{mg}$ sildenafil TDS. Outcomes were compared with those from matched contemporaneous sildenafil-naive pregnancies $(n=17)$.

Sildenafil treatment was associated with increased posttreatment fetal growth velocity in the AC $[9 / 10$ (treated) versus 7/17 (control); odds ratio, 12.9; 95\% CI, 1.3, 126]. However, it was unclear if the higher levels of termination and permissive stillbirth in the sildenafil-naive group reflect poorer prognosis or altered management.

Lin et al reported a decrease in uterine artery pulsatility and resolution of uterine artery notching following administration of sildenafil citrate to a case of IUGR diagnosed at 26 weeks of gestations. ${ }^{14}$ Contradictory to our findings, they also observed increase in EFW without maternal or neonatal adverse outcomes.

Wareing et al conducted a study where small artery dissected from myometrial biopsies obtained at cesarean section from normal pregnant women $(n=27)$ or women whose pregnancies were complicated by FGR $(n=12)$ were mounted on wire myographs. ${ }^{15}$ Vessels were constricted (with arginine vasopressin or U46619) and relaxed (with bradykinin) before and after incubation with a phosphodiesterase-5 inhibitor, sildenafil citrate. They concluded that sildenafil citrate improves endothelial function of myometrial vessels from women whose pregnancies are complicated by intrauterine growth restriction. Sildenafil citrate may offer a potential therapeutic strategy to improve uteroplacental blood flow in FGR pregnancies.

\section{Limitations}

This study design did not permit the analysis of neonatal and long-term morbidity and mortality, but it was imperative that future studies be designed to address these outcomes.

\section{CONCLUSION}

Sildenafil citrate is a promising treatment for IUGR fetuses with prolongation of pregnancy and improvement of fetal birth weight, umbilical Doppler indices (UDI), decreases days needed in PCU. 
Funding: No funding sources

Conflict of interest: None declared

Ethical approval: The study was approved by the Institutional Ethics Committee

\section{REFERENCES}

1. American College of Obstetricians and Gynecologists (ACOG) Practice bulletin no. 134: fetal growth restriction. Obstet Gynecol. 2013;121(5):1122-33.

2. Srinivas SK, Edlow AG, Neff PM, Sammel MD, Andrela CM, Elovitz MA. Rethinking IUGR in preeclampsia: dependent or independent of maternal hypertension. J Perinatol. 2009;29(10):680.

3. Downing JW, Ramasubramanian R, Johnson RF, Minzter BH, Paschall RL, Sundell HW, et al. Selective phosphodiesterase-5 inhibition improves outcome in preeclampsia. Med Hypotheses. 2012;63(6):1057-64.

4. Florio P, Marinoni E, DiIorio R, Bashir M, Ciotti S. Urinary S100B protein concentrations are increased in intrauterine growth-retarded newborns. Pediatrics. 2009; 118:747-54.

5. Gardosi J, Madurasinghe V, Williams M, Malik A, Francis A. Maternal and fetal risk factors for stillbirth: population based study. BMJ. 2013;346:108.

6. Turan OM, Turan S, Berg C, Gembruch U, Nicolaides $\mathrm{KH}$, Harman $\mathrm{CR}$, et al. Duration of persistent Abnormal ductus venosus flow and its impact on perinatal outcome in fetal growth restriction. Ultrasound Obstet Gynecol. 2011;38(3):295-302.

7. Royal collage of obstetrician and gynecologists (ROCG). Small for gestational age fetus, investigation and management (green top guidelines 31). 2014.
8. Militello M, Pappalardo EM, Ermito S, Dinatale A, Cavaliere A, Carrara S. Obstetric management of IUGR. J Prenat Med. 2009;3(1):6.

9. Panda S, Das A, Nowroz HM. Sildenafil citrate in fetal growth restriction. J Reprod Infertil. 2014;15(3):168-9.

10. El-Sayed MA, Saleh SA, Maher MA, Khidre AM. Utero-placental perfusion Doppler indices in growth restricted fetuses: effect of sildenafil citrate. J Matern Fetal Neonatal Med. 2018;31(8):1045.

11. Ferreira E, Léveillée D, Iglesias MH, Brochet MS. Sildenafil use during pregnancy for intrauterine growth restriction. a case series. J Obstet Gynaecol Canada. 2016;38(5):486.

12. Singh A, Daharwal A, Kujur, Awasthi P. Effect of sildenafil on IUGR. Int $\mathbf{J}$ Reproduct Contracept Obstetr Gynecol. 2017;6(5):1806.

13. Dadelszen P, Dwinnell S, Magee LA, Carleton BC, Gruslin A, Lee B, et al. Sildenafil citrate therapy for severe early-onset intrauterine growth restriction. BJOG. 2011;118(5):624-8.

14. Lin TH, Su YN, Shih JC, Hsu HC, Lee CN. Resolution of high uterine artery pulsatility index and notching following sildenafil citrate treatment in a growth-restricted pregnancy. Ultrasound Obstet Gynecol. 2012;40(5):609-10.

15. Wareing M, Myers JE, O'Hara M, Baker PN. Sildenafil citrate (Viagra) enhances vasodilatation in fetal growth restriction. J Clin Endocrinol Metab. 2005;90(5):2550-5.

Cite this article as: Fatah LEAE, Elnashar DA, Elabass ZMA, Ait-Allah AS. Sildenafil citrate for the management of asymmetrical intrauterine growth restriction and its effect on umbilical artery Doppler. Int J Reprod Contracept Obstet Gynecol 2022;11:714-9. 